\title{
Free Radicals in the Thermally Sterilized Aminoglycoside Antibiotics
}

\author{
Paweł Ramos $^{1 *}$, Barbara Pilawa ${ }^{1}$, Andrzej Krztoń ${ }^{\text {and Barbara Liszka }}{ }^{2}$
}

${ }^{1}$ Medical University of Silesia in Katowice, School of Pharmacy and Laboratory Medicine, Department of Biophysics, Jedności 8, 41-200 Sosnowiec, Poland

${ }^{2}$ Centre of Polymer and Carbon Materials, Polish Academy of Sciences, Marii Curie Skłodowskiej 34, 41-819 Zabrze, Poland

\begin{abstract}
Changes of the chemical structure and free radicals formation in aminoglycoside antibiotics during sterilization at temperatures $160^{\circ} \mathrm{C}, 170^{\circ} \mathrm{C}$, and $180^{\circ} \mathrm{C}$ according to the pharmacological norms were studied. EPR and DRIFT spectroscopy were applied as experimental methods. It was demonstrated that free radicals are formed in streptomycin, gentamicin, neomycin, sisomicin, paromomycin, and tobramycin during thermal sterilization. Complex free radicals system with the complex shape of EPR spectra characterized the tested samples. Mainly oxygen free radicals exist in the tested heated antibiotics. The EPR lines of the analyzed antibiotics are homogeneously broadened. Fast spin-lattice relaxation processes exist in the examined sterilized aminoglycoside antibiotics. Free radicals concentrations in the aminoglycoside antibiotics depend on the temperature and time of sterilization. The highest free radicals concentrations characterize thermally sterilized sisomicin. Streptomycin, gentamicin, neomycin, paromomycin, and tobramycin may be sterilized at temperatures $160^{\circ} \mathrm{C}, 170^{\circ} \mathrm{C}$ and $180^{\circ} \mathrm{C}$. Sisomicin should be sterilized at temperature $180^{\circ} \mathrm{C}$. Free radicals concentration changes during storage of the examined antibiotics, and probably interactions with oxygen molecules may be responsible for this effect. DRIFT studies shown that sterilization conditions, the temperature and the presence of oxygen, causes only small changes in the chemical structure of aminoglycoside antibiotics by alteration of the functional groups. EPR and DRIFT methods are proposed to optimization of the thermal sterilization process of drugs and conditions of their storage.
\end{abstract}

Keywords: Aminoglycoside antibiotics; Thermal sterilization; Free radicals; EPR; DRIFT

\section{Introduction}

Process of sterilization is preformed to kill microorganisms in drugs and to rise the safety of the pharmacotherapy [1-3]. The one of the popular methods is the thermal sterilization by the use of hot air circulation in the drug samples [1-3]. The parameters of the thermal sterilization are fitted to the resistance of microorganisms and they are regulated by the norms $[2,3]$. Thermal sterilization may be done for the drugs resistant to temperature interactions. It was shown by us earlier that thermal treatment may be used to sterilize prednizolone [4], diclofenac [5], tramadole [6] and isosorbidedinitrate [7].

Thermal sterilization should not produce the high amounts of free radicals in the drugs and should not considerably change their chemical structure. Free radicals as the molecules containing unpaired electrons may be responsible for toxic effects in organism [8]. Both free radicals and the changed chemical units in the drugs may decrease their pharmaceutical effectiveness in human tissues.

The aim of this work is to find optimal conditions of thermal sterilization of the analysed aminoglycoside antibiotics. The usefulness of Electron Paramagnetic Resonance (EPR) and Diffuse Reflectance Infrared Fourier Transform (DRIFT) Spectroscopy for testing influence of the sterilization temperature on chemical structure and paramagnetic nature of the drugs are presented.

\section{Experimental}

\section{Samples}

Free radicals in the following aminoglycoside antibiotics: streptomycin, gentamicin, neomycin, sisomicin, paromomycin, and tobramycin, sterilized at different conditions according to the pharmaceutical norms $[2,3]$ were examined. The antibiotic samples were heated at temperature $160^{\circ} \mathrm{C}$ for 120 minutes, $170^{\circ} \mathrm{C}$ for 60 minutes, and $180^{\circ} \mathrm{C}$ for 30 minutes. Sterilization was performed in hot air oven with air circulation.
Chemical structures of the tested aminoglycoside antibiotics are presented in figure 1 [9]. Aminoglycoside antibiotics constitute a large and clinically important group of bactericidal antibiotics. The mechanism of action of aminoglycoside antibiotics are irreversible binding to the $30 \mathrm{~S}$ ribosomal subunit, thereby inhibiting bacterial proteinsynthesis. In addition, these drugs damage the cytoplasmic membrane of bacteria sensitive to them $[10,11]$.

Streptomycin is an aminoglycoside antibiotic natural origin. This drug is used most often in the form of streptomycinsulfate. Streptomycin has bactericidal activity. It is mainly used to treat tuberculosis $[10,11]$.

Gentamicin is aminoglycoside antibiotic of natural origin, used most often in cases of serious infections Gram-negative bacilli. Gentamicin in pharmacy is prepared in the form of sulfate [10,11].

Neomycin is an aminoglycoside antibiotic, another of natural origin, used in the treatment of superficial infections caused by staphylococci or Gram-negative bacteria. Of the three isomeric forms of neomycin: A, $\mathrm{B}$ and $\mathrm{C}$ in the medicine is used mainly in the form of isomer Bsulfate. Neomycin with bacitra $\mathrm{c}$ in natamicin and hydrocortisone occurs in a complex composition of drugs [10,11].

Sisomicinuse in urinary tract infections, infections associated burns, inflammation of meningitis and inflammation of the prostate

*Corresponding author: Paweł Ramos, Medical University of Silesia in Katowice School of Pharmacy and Laboratory Medicine, Department of Biophysics, Jedności 8, 41-200 Sosnowiec, Poland, Tel: +48 3236411 64; Fax: +48 323641160 E-mail: pawelramos@sum.edu.pl

Received November 15, 2012; Accepted November 28, 2012; Published November 30, 2012

Citation: Ramos P, Pilawa B, Krztoń A, Liszka B (2012) Free Radicals in the Thermally Sterilized Aminoglycoside Antibiotics. Pharmaceut Anal Acta 3: 193. doi:10.4172/2153-2435.1000193

Copyright: $\odot 2012$ Ramos $P$, et al. This is an open-access article distributed unde the terms of the Creative Commons Attribution License, which permits unrestricted use, distribution, and reproduction in any medium, provided the original author and source are credited. 
gland caused by Pseudomonasaeruginosa,Enterobacter, Proteus, Staphylococcus aureus, Escherichia coli and Klebsiellapneumoniae $[10,11]$.

Paromomycinis used in gastrointestinal infections caused by Gramnegative bacteria, prior treatments for the large intestine, and tape worm infection. Paromomycin induces nephrotoxicity and ototoxicity, which is the reason for its withdrawal from use as a pharmacological agent $[10,11]$.

Tobramycin is used by inhalation in patients with cystic fibrosis and topically in the treatment of external infections of the eye and adnexa. Tobramycin acts primarily on the destructive bacteria Pseudomonas aeruginosa $[10,11]$ (Figure 1).

\section{Methods}

\section{EPR spectroscopy}

Free radicals were examined by the use of electron paramagnetic resonance (EPR) spectroscopy. For EPR measurements the powdered samples of the original and the sterilized aminoglycoside antibiotics were placed in the thin walled glass tubes with the external diameter of $3 \mathrm{~mm}$. Mass of these samples located in the tubes were measured. EPR signals were not observed for the empty tubes. Free radicals properties and their concentrations in the samples were tested.

EPR spectra of the antibiotics were measured by an X-band (9.3 $\mathrm{GHz}$ ) electron paramagnetic resonance spectrometer with magnetic modulation of $100 \mathrm{kHz}$ produced by Radiopan Firm (Poznań, Poland). To avoid microwave saturation EPR lines were recorded at low microwave power of $0.7 \mathrm{~mW}$ and high attenuation of $20 \mathrm{~dB}$.

For the original and the sterilized antibiotics the lineshape and the parameters of the EPR spectra were analyzed. For the studied samples the following parameters of EPR spectra were determined: $g$-factors, amplitudes $(\mathrm{A})$, integral intensities $(\mathrm{I})$, and linewidths $\left(\Delta \mathrm{B}_{\mathrm{pp}}\right)$. Amplitude and integral intensity are dependent on free radicals concentration in the samples [12]. Linewidth depend on magnetic interactions in the samples [12].

$\mathrm{g}$-Values were calculated from the equation of resonance condition according to the formula [12]:

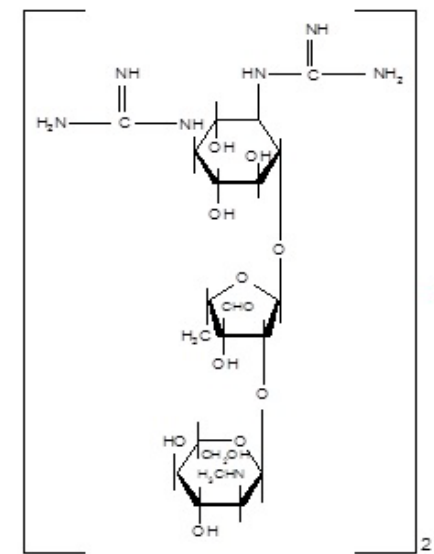

a

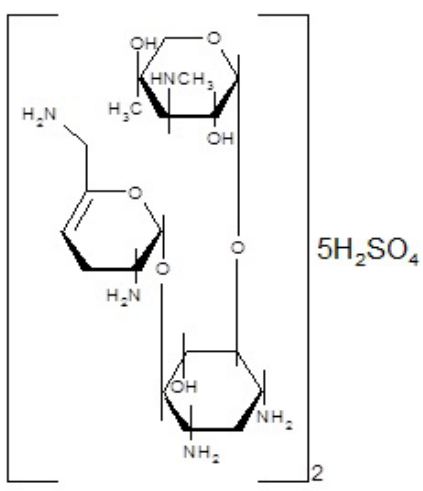

d
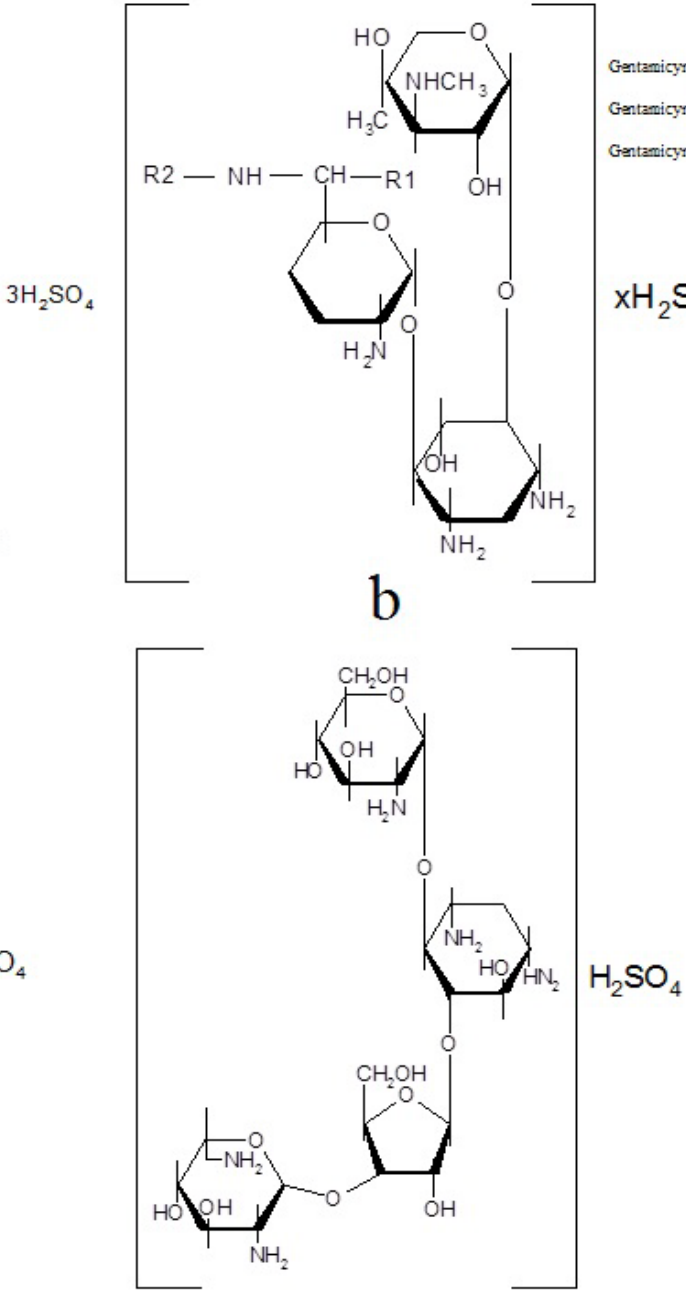

e
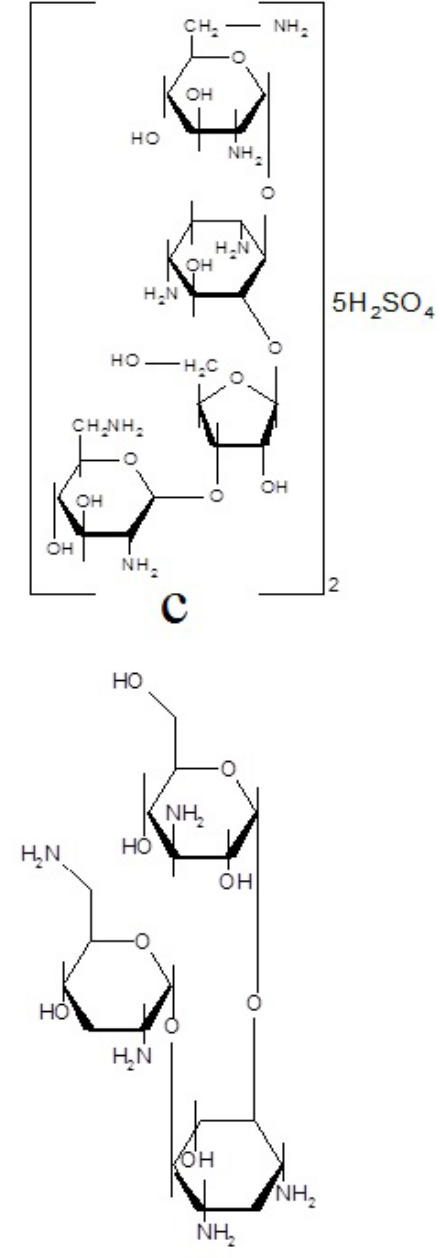

f

Figure 1: Chemical structures of streptomycin (a), gentamicin (b), neomycin (c), sisomicin (d), paromomycin (e) and tobramycin (f) [9]. 


$$
\mathrm{g}=\mathrm{h} v / \mu_{\mathrm{B}} \mathrm{B}_{\mathrm{r}}
$$

where: h-Planck constant, $\nu$-microwave frequency, $\mu_{B}-B o h r$ magneton, $\mathrm{B}_{\mathrm{r}}$-resonance magnetic field. Microwave frequency $(v)$ was directly measured by MCM101 recorder produced by Eprad Firm (Poznań, Poland). The $\mathrm{B}_{r}$ values were obtained from the EPR spectra.

Effect of microwave power in the range of $2.2-70 \mathrm{~mW}$ on $\mathrm{EPR}$ spectra was examined. Changes of amplitudes (A), integral intensities $(\mathrm{I})$, and linewidths $\left(\Delta \mathrm{B}_{\mathrm{pp}}\right)$ with microwave power were obtained.

Spin-lattice relaxation processes in the samples were characterized by observation of microwave saturation of their EPR lines. Power of microwave saturation of EPR lines increases with fastening of spinlattice relaxation processes [12].

The parameter $\mathrm{A}_{1}-\mathrm{A}_{2}$ of lineshape of the EPR spectra was analyzed. The values of $A_{1}$ and $A_{2}$ are presented in figure 6 .

The lineshape parameter $A_{1}-A_{2}$ was determined for the EPR spectra recorded in the range of microwave power $2.2-70 \mathrm{~mW}$. The changes of the shape of EPR spectra with microwave power were tested. According to the theory of electron paramagnetic resonance [12] the shape of EPR spectra changes with the increasing of microwave power for the samples with the several types of free radicals.

Concentrations of free radicals $(\mathrm{N})$ in the studied samples were compared. The concentration was determined as the value proportional to the integral intensity (I) of EPR spectrum $[12,13]$. The integral intensities were obtained by double integration of the first-derivative EPR spectra. Ultramarine was used as the reference for concentration of free radicals. The integral intensities of the EPR lines of the examined antibiotics and the integral intensity of the ultramarine line were compared. The second reference - a ruby crystal $\left(\mathrm{Al}_{2} \mathrm{O}_{3}: \mathrm{Cr}^{3+}\right)$ was permanently placed in a resonance cavity. For each sample and for the reference - ultramarine the EPR line of a ruby crystal was detected. The same receiver gain and the same microwave power were used. The free radicals concentration $(\mathrm{N})$ was determined as follow:

\section{$\mathrm{N}=\mathrm{N}_{\mathrm{u}}\left[\left(\mathrm{W}_{\mathrm{u}} \mathrm{A}_{\mathrm{u}}\right) / \mathrm{I}_{\mathrm{u}}\right] \times[\mathrm{I} /(\mathrm{WAm})]$, where}

$\mathrm{N}_{\mathrm{u}}$ - the number of paramagnetic center $\left(1.2 \times 10^{19} \mathrm{spin}\right)$ in the ultramarine reference,

$\mathrm{W}$ and $\mathrm{W}_{\mathrm{u}}$ - the receiver gains for sample and the ultramarine,

$A$ and $A_{u}$ - the amplitudes of ruby signal for the sample and the ultramarine,

I and $I_{u}$ - the integral intensities for the sample and ultramarine,

$\mathrm{m}$ - the mass of the sample.

\section{DRIFT spectroscopy}

The Diffuse Reflectance Infrared Fourier Transform (DRIFT) technique allows for more detailed structural and compositional analysis of organic materials. The DRIFT is particularly useful in the investigations of powdered samples. Great advantage of the DRIFT is fast and easy sampling because little or no sample preparation is required.

The Kubelka-Munk function (KM) permits linearize sample intensity with their concentration in non-absorbing matrix e. g. potassium bromide ( $\mathrm{KBr})$. The Kubelka-Munk function is as follows:

$$
\mathrm{KM}=\frac{\left(1-R_{\infty}\right)^{2}}{2 R_{\infty}}=\frac{c}{k}
$$

where, $R_{\infty}$ is the absolute reflectance of the layer, $c$ is the concentration and $k$ is the molar absorption coefficient [14].

DRIFT spectra were recorded with a FTS-165 Bio-Rad spectrometer, using Harrick Praying Mantis diffuse reflectance accessory, by coadding 256 scans in the range $4000-400 \mathrm{~cm}^{-1}$ at a resolution of $4 \mathrm{~cm}^{-1}$. The samples were grinded and mixed in agate mortar withanhydrous potassium bromide in the proportion $5 / 95$ by weight.

\section{Results}

EPR study shows that the original aminoglycoside antibiotic samples are diamagnetic and free radicals were not detected. EPR spectra were not measured for the original samples even at the highest receiver gains of the spectrometer and the highest microwave power $(70 \mathrm{~mW})$. The paramagnetic defects do not exist in the original drug samples.

EPR spectra were observed for all the thermally sterilized aminoglycoside antibiotics. The EPR spectra of streptomycin (a), gentamicin (b), neomycin (c), sisomicin (d), paromomycin (e), and tobramycin (f), sterilized at $160^{\circ} \mathrm{C}(120$ minutes $), 170^{\circ} \mathrm{C}(60$ minutes $)$, and $180^{\circ} \mathrm{C}$ (30 minutes) measured with microwave power of $2.2 \mathrm{~mW}$ at room temperature 20 minutes after sterilization are presented in figure 2. Amplitudes (A) and linewidths $\left(\Delta \mathrm{B}_{\mathrm{pp}}\right)$ of these EPR spectra are compared in figure 3 .

Free radicals are formed in streptomycin, gentamicin, neomycin, sisomicin, paromomycin, and tobramycin in the process of thermal sterilization at temperatures $160^{\circ} \mathrm{C}, 170^{\circ} \mathrm{C}$ and $180^{\circ} \mathrm{C}$. Free radicals concentrations $(\mathrm{N})$ and the parameters of the EPR spectra are shown in figure 4.

Electron Paramagnetic Resonance study indicates that free radicals in the sterilized aminoglycoside antibiotics reveal the specific properties. Free radicals system with the complex shape of EPR spectra reveals the complex character. The EPR spectra are asymmetrical and the parameters of the asymmetry changes with microwave power (Figure 5). Several groups of free radicals exist in the samples. Mainly oxygen free radicals exist in the tested heated antibiotics (Figure 4). Homogeneous broadening of EPR lines, proved by the continuous microwave saturation of the resonance signals (Figures 6 and 7). Fast spin-lattice relaxation processes without microwave saturation of the EPR lines in the used range of microwave powers (Figure 8).

Free radicals concentrations in the aminoglycoside antibiotics depend on the temperature and time of sterilization (Figure 4). The highest free radicals concentrations characterize thermally sterilized sisomicin.

Streptomycin, gentamicin, neomycin, paromomycin, and tobramycin may be sterilized at temperatures $160^{\circ} \mathrm{C}, 170^{\circ} \mathrm{C}$ and $180^{\circ} \mathrm{C}$ (Figure 4). For sisomicin thermal sterilization at temperature $180^{\circ} \mathrm{C}$ for is recommended (Figure 4).

Free radicals concentrations changes during storage of the examined antibiotics, and probably interactions with oxygen molecules may be responsible for this effect (Figure 9).

DRIFT spectra of the original and thermally sterilized exemplary antibiotics at $160^{\circ} \mathrm{C}, 170^{\circ} \mathrm{C}$ and $180^{\circ} \mathrm{C}$ are compared in figures 10 and 11. These spectra were recorded for selected aminoglycoside antibiotic such as neomycin and streptomycin.

In the DRIFT spectra of both antibiotics the bands corresponding to the $\mathrm{O}-\mathrm{H}$ (hydroxyl group) stretching vibration and $\mathrm{C}-\mathrm{O}-\mathrm{C}$ (ether 

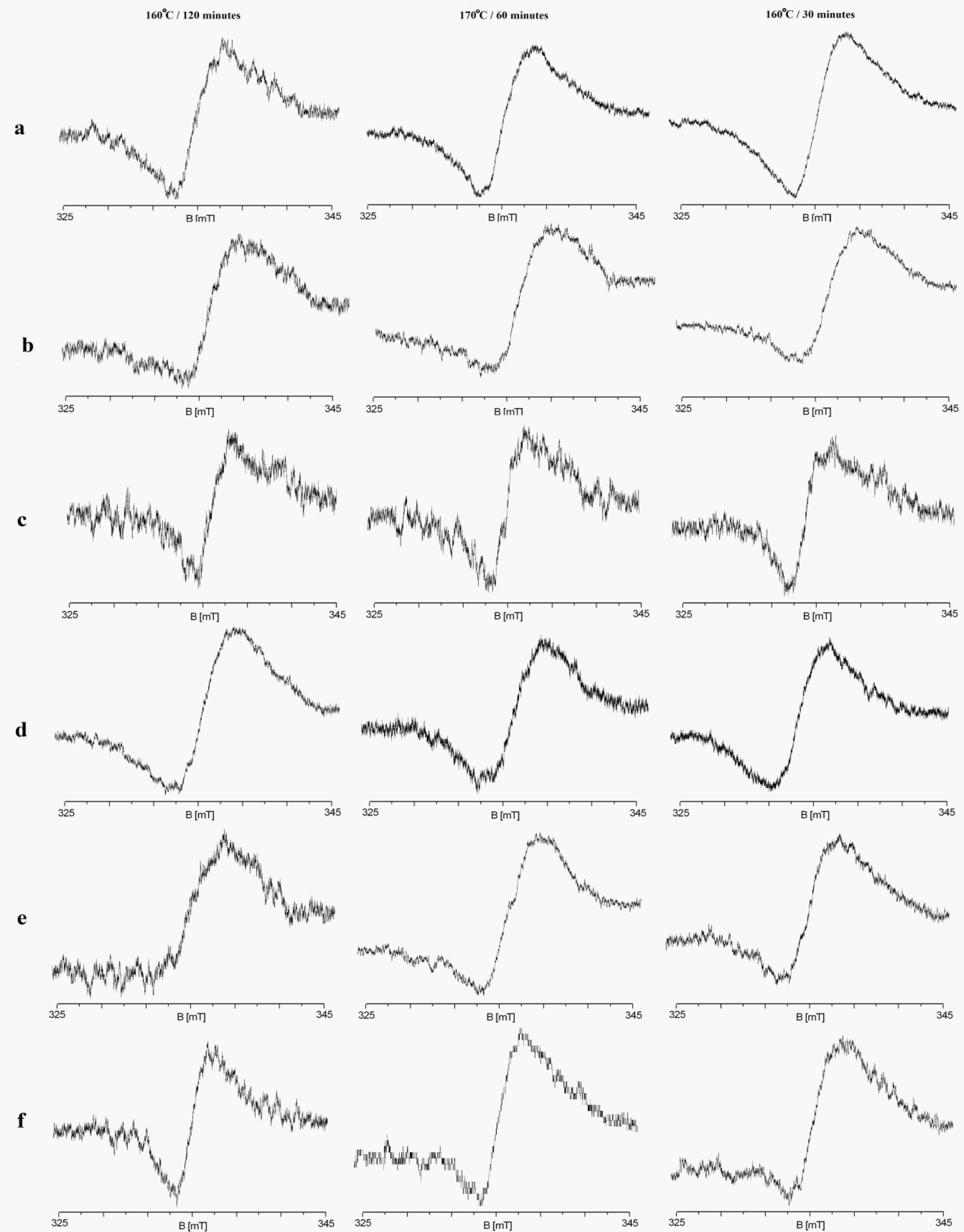

Figure 2: EPR spectra of streptomycin (a), gentamicin (b), neomycin (c), sisomicin (d), paromomycin (e), and tobramycin (f), sterilized at $160^{\circ} \mathrm{C}(120$ minutes), $170^{\circ} \mathrm{C}$ (60 minutes), and $180^{\circ} \mathrm{C}$ (30 minutes). The EPR spectra were measured with microwave power of $2.2 \mathrm{~mW}$ at room temperature 20 minutes after sterilization. 


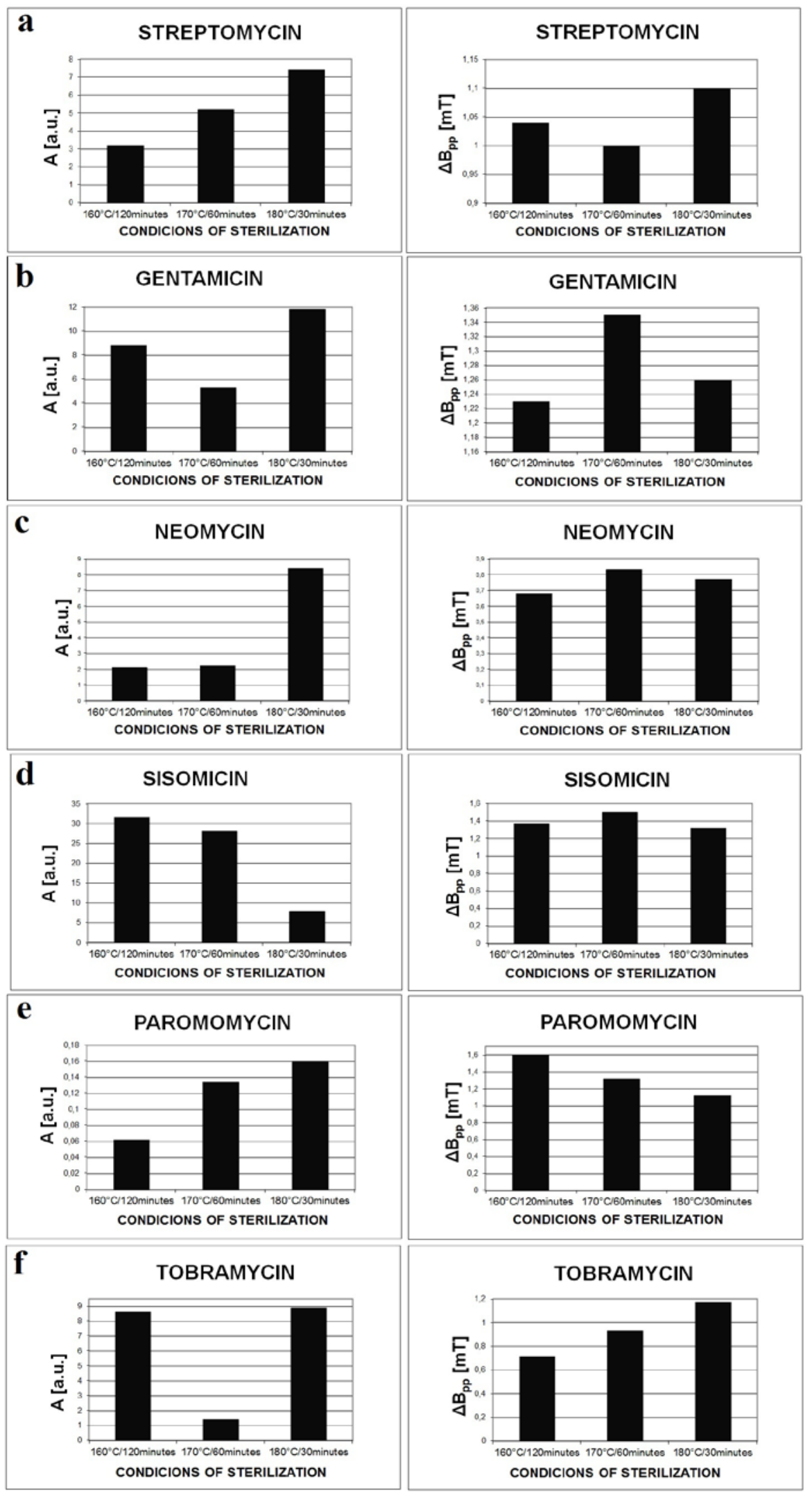

Figure 3: Amplitudes $(A)$ and linewidths $(\triangle B$ ) of EPR spectra of streptomycin (a), gentamicin (b), neomycin (c), sisomicin (d), paromomycin (e), and tobramycin (f), sterilized at $160^{\circ} \mathrm{C}\left(120\right.$ minutes), $170^{\circ} \mathrm{Cp}\left(60\right.$ minutes), and $180^{\circ} \mathrm{C}(30$ minutes). The EPR spectra were measured with microwave power of $2.2 \mathrm{~mW}$ at room temperature 20 minutes after sterilization. 


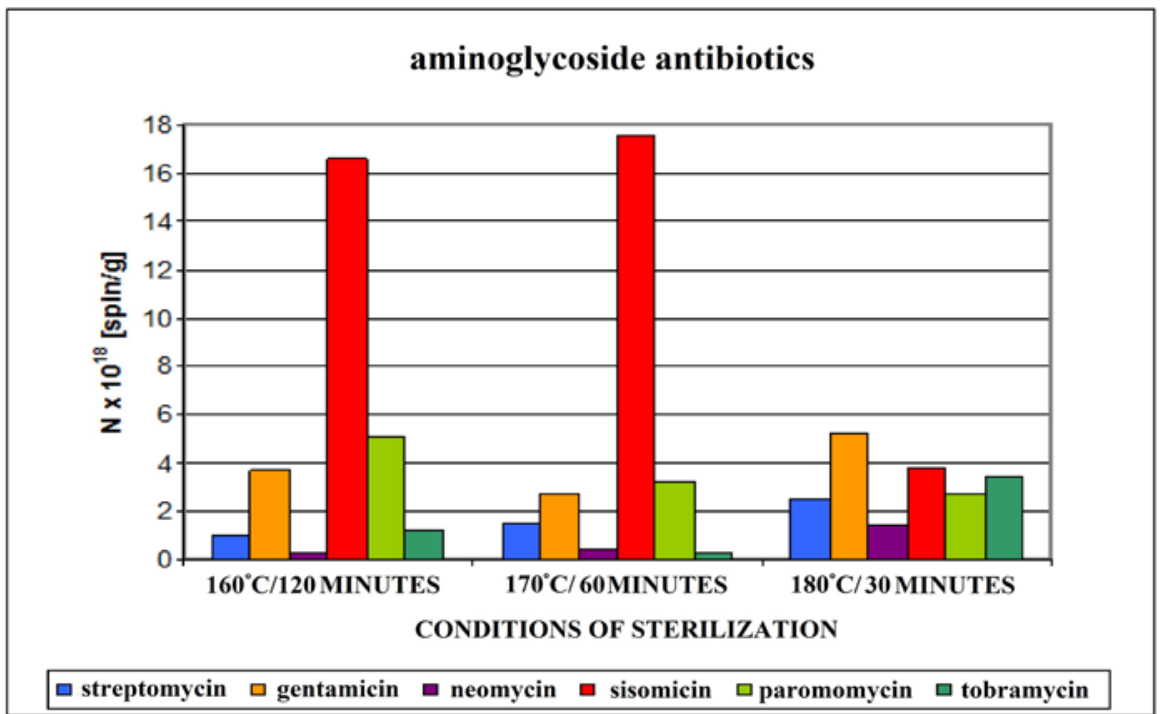

Figure 4: Comparison of free radicals concentrations $(\mathrm{N})$ in the studied antibiotics. The data for samples storage 20 minutes after sterilization.

group) stretching vibration can be attributed to the same strong bands at about 1109 and about $1067 \mathrm{~cm}^{-1}$. The characteristic band for the amine $(\mathrm{N}-\mathrm{H})$ bond deformation will appear at $1608 \mathrm{~cm}^{-1}$ for neomycin and 1676 ed for streptomycin. The peaks at 1516 and $1627 \mathrm{~cm}^{-1}$ (Figures 10 and 11 ), respectively are related to $\mathrm{C}-\mathrm{N}$ stretching vibration. In addition the broad band could be envisaged in the range of 3329-3188 $\mathrm{cm}^{-1}$, indicative of the presence of $\mathrm{N}-\mathrm{H}$ stretching vibration (amine group) and $\mathrm{O}-\mathrm{H}$ stretching vibration in the sample of streptomycin [1518]. For neomycin the band position of the $-\mathrm{NH}_{2}$ and $-\mathrm{OH}$ groups is doubtfully (the broad band not show specific absorption).

It can be noticed that small differences between DRIFT spectra of the original antibiotic and sterilized samples was observed. However, for determining the fine changes of chemical structure in the samples the differential spectra were constructed by subtracting original sample spectrum from temperature treated sample spectrum (Figure 12-17). No significant differences are observed in DRIFT difference spectrum results from subtraction spectrum of the neomycin sterilized at $160^{\circ} \mathrm{C}$ and original neomycin (Figure 12). However some changes in the chemical structure of neomycin can be observed for the spectrum of sample treated at $170^{\circ} \mathrm{C}$. It is noticed the slightly decreasing the peak at $1107 \mathrm{~cm}^{-1}$ corresponding to the hydroxyl group or ether group (Figure 13). The intensity of this peak decrease more considerable on spectrum of the sample sterilized at $180^{\circ} \mathrm{C}$ (Figure 14).

DRIFT spectra of sterilized streptomycin (Figures 15-17) indicate the increasing the peaks assigned to $\mathrm{O}-\mathrm{H}$ stretching vibration (about $3330 \mathrm{~cm}^{-1}$ ), $\mathrm{O}-\mathrm{H}$ bending vibration (about $1114 \mathrm{~cm}^{-1}$ ) and $\mathrm{C}=\mathrm{O}$ stretching vibration (about $1663 \mathrm{~cm}^{-1}$ ).

The performed spectroscopic studies broaden our knowledge about free radicals in the sterilized antibiotics. EPR and DRIFT methods may be used for optimization of thermal sterilization process of drugs and conditions of their storage.

\section{Discussion}

The performed electron paramagnetic resonance and infrared studies indicate that these spectroscopic methods are very useful in the process of drugs preparation. The process of production of drugs should be accompanied by the minimal free radicals formation and their chemical structures should be unchanged. These two aspects, low contents of free radicals and the pure chemical units, are the important condition to proper interaction of the drugs in the human organism during pharmacotherapy. The other important problem is the possibility of characterization of the chemical structure of the tested drugs. The EPR and DRIFT spectroscopic methods are proposed by as the additional experimental laboratory's works before the drug preparation in the industrial production. The possibilities of these two spectroscopic methods are the best presented by the obtained results for the exemplary group of drug, which were studied in this work and which are discussed below.

The first stage of examination of the sterilized drugs is to check their paramagnetic or diamagnetic character. Our EPR analysis shows that the aminoglycoside antibiotics are diamagnetic before sterilization. This result is the confirmation of the chemical purity of the tested samples which were taken as the representative drugs. The EPR spectra are observed only for paramagnetic samples, which contain unpaired electrons, for example unpaired electrons of free radicals [12]. The paramagnetic samples were located in the resonance cavity of the electron paramagnetic resonance spectrometer absorbs microwaves of the proper frequency fitted to the energy levels of the unpaired electrons in magnetic field. The absorbed energy increases with increasing of the amount of unpaired electrons in the paramagnetic samples [12]. Chemical structures of the analysed aminoglycoside antibiotics (Figure 1) [9] indicate that the absence of unpaired electrons is expected in the original samples. The ruptured chemical bonds, so also the unpaired electrons, were not detected in the original aminoglycoside antibiotics, because for all the tested samples EPR spectra were not obtained.

Paramagnetism appears in the analysed aminoglycoside antibiotics during the thermal sterilization process. The EPR spectra were obtained for streptomycin (Figure 2a), gentamicin (Figure 2b), neomycin (Figure $2 \mathrm{c}$ ), sisomicin (Figure 2d), paromomycin (Figure 2e), and tobramycin (Figure 2f), sterilized at $160^{\circ} \mathrm{C}, 170^{\circ} \mathrm{C}$, and $180^{\circ} \mathrm{C}$. The parameters of the spectra: amplitudes $(\mathrm{A})$ and linewidths $\left(\Delta \mathrm{B}_{\mathrm{pp}}\right)$, depend on the sterilization conditions (Figure 3 ). It can be seen that independently on the sterilization conditions the chemical bonds are ruptured in 
Citation: Ramos P, Pilawa B, Krztoń A, Liszka B (2012) Free Radicals in the Thermally Sterilized Aminoglycoside Antibiotics. Pharmaceut Anal Acta 3: 193. doi:10.4172/2153-2435.1000193

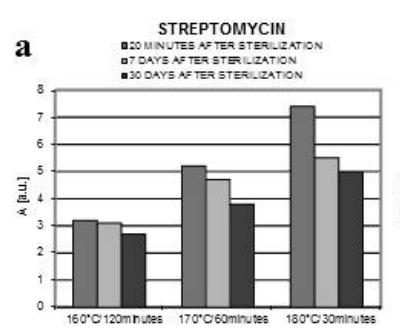

CONDIIONS OF STERILZATION

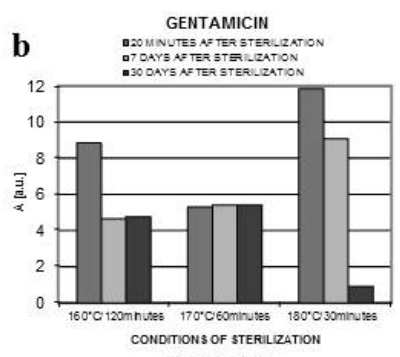

NEOMYCINA
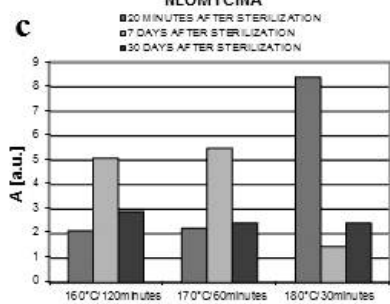

CONDOTONS OF STERLLZZTION

SISOMICIN

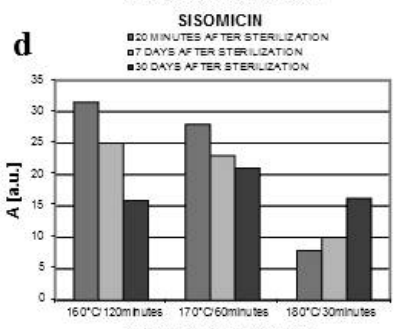

CONDTIONS OF STERLLZATION

PARAMOMYCIN

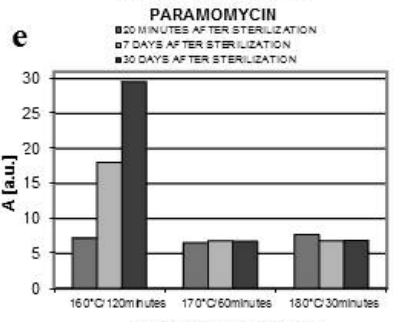

CONDITONS OF STERILZATION

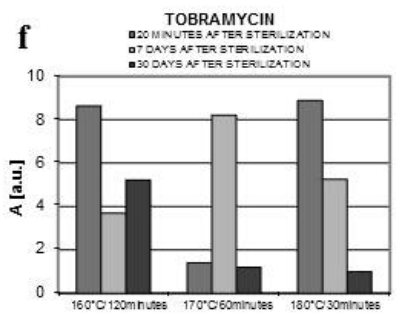

CONDTIONS OF STERILZATION

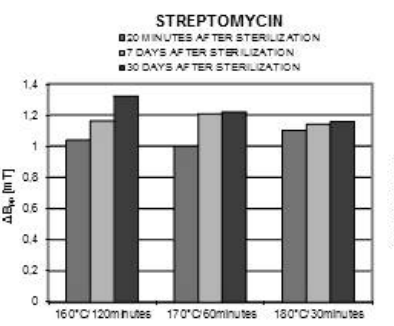

CONDTIONS OF STERLIZZTION

GENTAMICIN

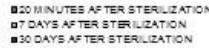

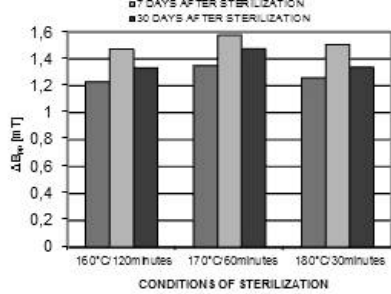

CONDTTONS OF STERILZ

aมOMNUTES $A$ TER STERUIZ,

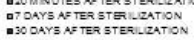

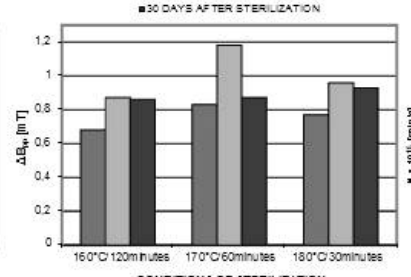

CONDTIONS OF STERLLZATION

SISOMICIN

DT OAYS AETER STE SILZATION

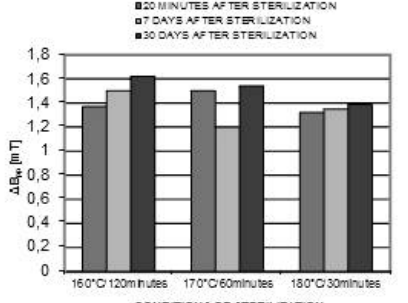

CONDITONS OF STERLLZATION

PARAMOMYCIN
aOOMUTES $N$ F TES STER

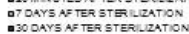

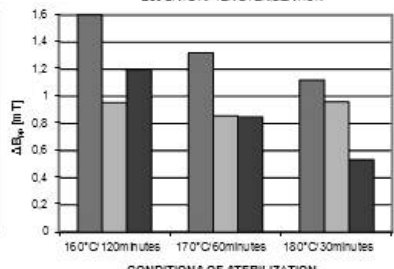

CONDITONS OF STERLLZATIO

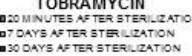

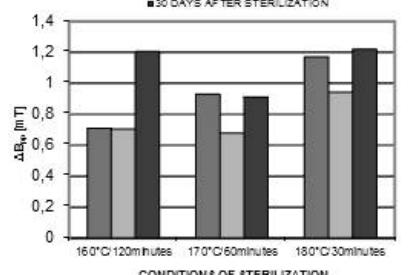

CONDTIONS OF STERLIZATION

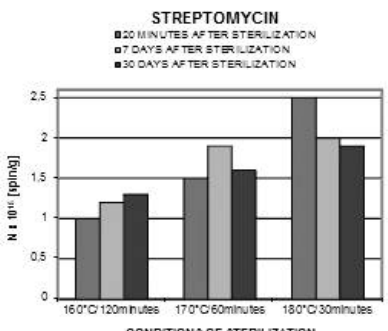

GENTAMICIN

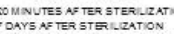

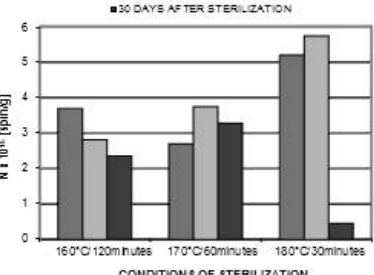

NEOMYCINA
NEOTIOF OTERLZATI

TOMNUTES AETER STER

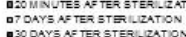

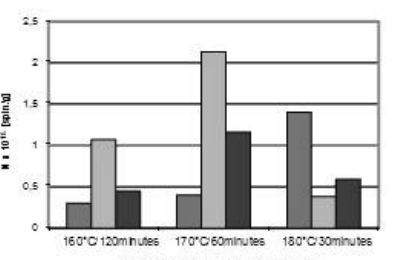

CONDTIONS OF STERLLZATION

SISOMICIN

D.
DT OANS N TER STERILATTON

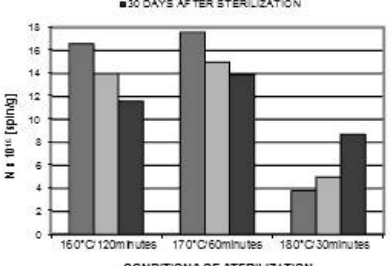

CONDTIONS OF STERILZATION

PARAMOMYCIN
PARAM

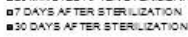

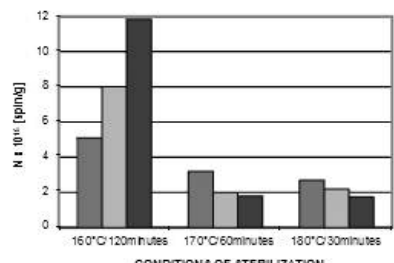

CONDTIONS OF STERLLZATION

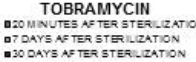

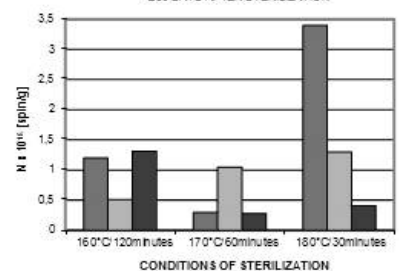

Figure 5: Changes amplitudes $(A)$ and linewidths $\left(\Delta B_{p p}\right)$ of EPR spectra, and free radicals concentrations (N) in streptomycin (a), gentamicin (b), neomycin (c), sisomicin (d), paromomycin (e), and tobramycin (f), sterilized at $160^{\circ} \mathrm{C}\left(120\right.$ minutes), $170^{\circ} \mathrm{C}(60$ minutes $)$, and $180^{\circ} \mathrm{C}(30$ minutes) with storage time after sterilization. The data for the EPR spectra measured with microwave power of $2.2 \mathrm{~mW}$ at room temperature. 
Citation: Ramos P, Pilawa B, Krztoń A, Liszka B (2012) Free Radicals in the Thermally Sterilized Aminoglycoside Antibiotics. Pharmaceut Anal Acta 3: 193. doi:10.4172/2153-2435.1000193
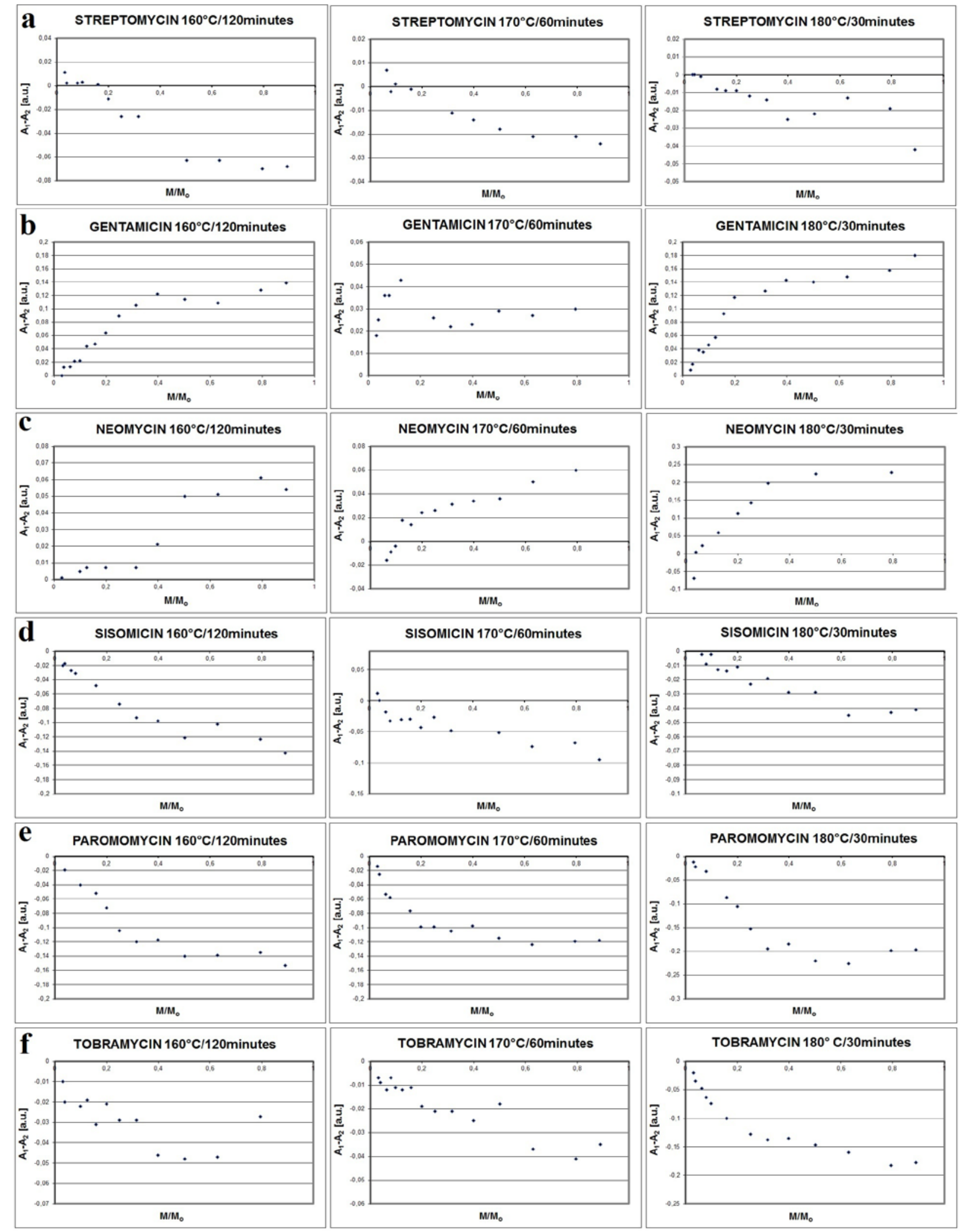

Figure 6: Effect of microwave power ( $M / \mathrm{M}_{\mathrm{o}}$ ) on lineshape parameter $\mathrm{A}_{1}-\mathrm{A}_{2}$ of EPR spectra of streptomycin (a), gentamicin (b), neomycin (c), sisomicin (d), paromomycin (e), and tobramycin (f), sterilized at $160^{\circ} \mathrm{C}\left(120\right.$ minutes), $170^{\circ} \mathrm{C}$ ( 60 minutes), and $180^{\circ} \mathrm{C}$ (30 minutes). The data for the EPR spectra measured at room temperature 20 minutes after sterilization. 

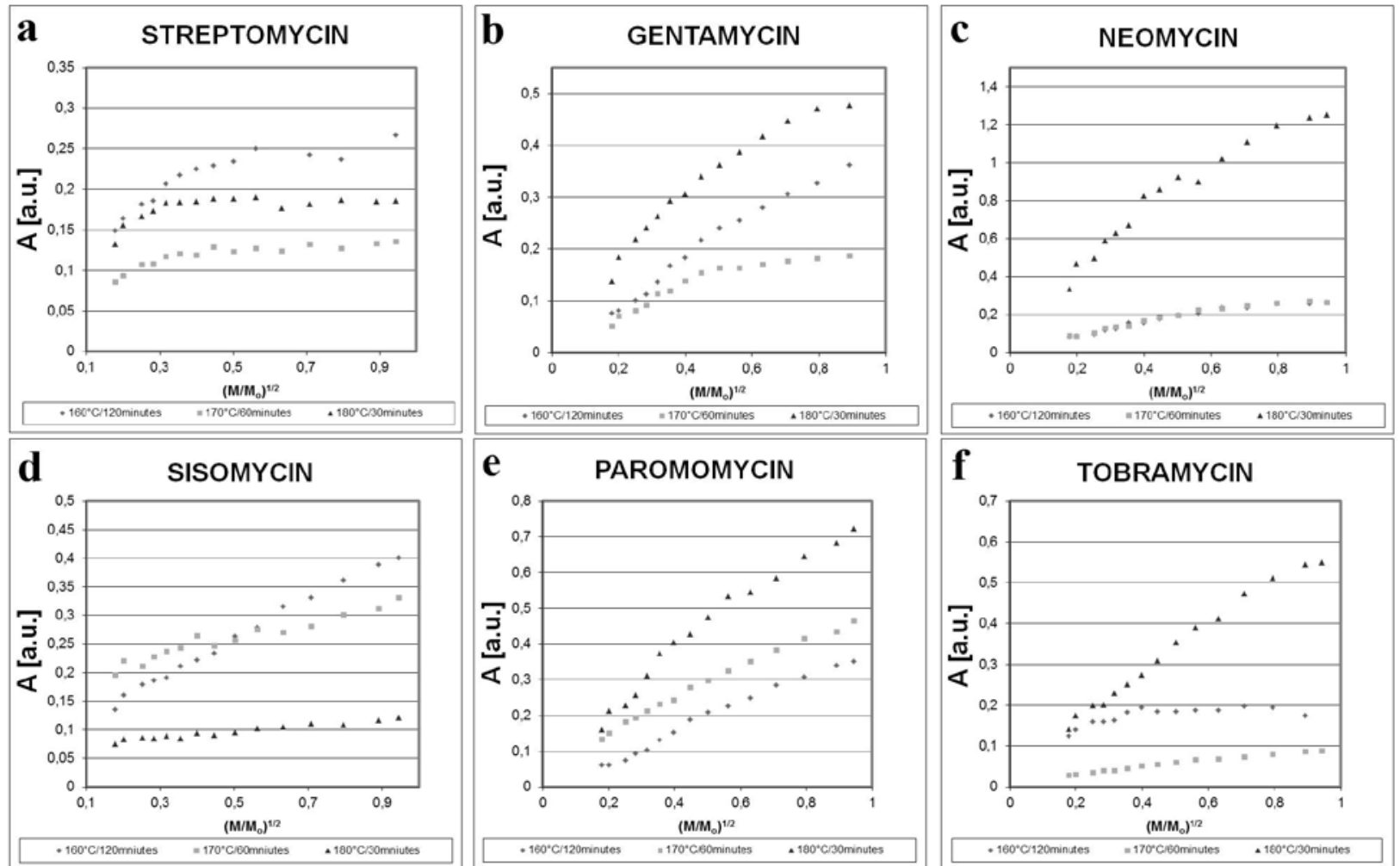

Figure 7: Effect of microwave power (M/Mo $)$ on amplitudes (A) of EPR spectra of streptomycin (a), gentamicin (b), neomycin (c), sisomicin (d), paromomycin (e), and tobramycin (f), sterilized at $160^{\circ} \mathrm{C}(120$ minutes $), 170^{\circ} \mathrm{C}(60$ minutes $)$, and $180^{\circ} \mathrm{C}(30$ minutes $)$. The data for the EPR spectra measured at room temperature 20 minutes after sterilization.

the analysed aminoglycoside antibiotics and the free radicals are formed. The sterilizations conditions were chosen according to the pharmaceutical norms [2,3], but the transformation from dia- to paramagnetic form of these drugs is clear visible. This aspect of the unexpected paramagnetism of the thermally sterilized drugs is not noticed in the norms $[2,3]$. The existence of free radicals in the sterilized drugs is one of the main problems, which should be resolved. Free radicals may be responsible for the dangerous interactions in tissues [8], so their concentrations in the substances, which contacts with them may be minimized. We propose to search the conditions of thermal sterilization, such as temperature and time, which give in the effect the lowest free radicals concentrations in the drugs after sterilization. This examination may be done in laboratories by the use of electron paramagnetic resonance spectrometer, or in the future in the industrial firms before sterilization of the individual drugs by the EPR spectrometer of the lower dimensions. Such a little EPR spectrometer with the lower electromagnet is used in the industry, for example to test the food products. The EPR spectroscopic analysis is proposed as the additional to examination of microorganisms in the drugs.

The main value, which is interested for the sterilized drugs, is the free radicals concentration $(\mathrm{N})$. Free radicals concentrations for the tested thermally sterilized aminoglycoside antibiotics are compared in figure 4. Independently to the sterilization temperature or times, the highest free radicals concentrations were obtained for sisomicin. Thermal sterilization is not the best method of sterilization for sisomicin, but the relatively best conditions of thermal sterilization may be pointed out. The lowest free radicals concentrations were obtained for sisomicin sterilized at temperature of $180^{\circ} \mathrm{C}$ during 30 minutes, so this temperature and this time of sterilization may be proposed for this antibiotic. The relatively lower free radicals concentrations characterize the others anlaysed aminoglycoside antibiotics: streptomycin, gentamicin, neomycin, paromomycin, and tobramycin sterilized at all temperatures $\left(160^{\circ} \mathrm{C}, 170^{\circ} \mathrm{C}\right.$, and $180^{\circ} \mathrm{C}$ ) (Figure 4) according to the pharmaceutical norms [2,3]. For example, only small changes of chemical structure of neomycin and streptomycin heated at $160^{\circ} \mathrm{C}$, $170^{\circ} \mathrm{C}$, and $180^{\circ} \mathrm{C}$, are presented via the comparison of its DRIFT spectra (Figures 10-17).

DRIFT studies indicate that sterilization of neomycin at $170^{\circ} \mathrm{C}$ and $180^{\circ} \mathrm{C}$ and sterilization of streptomycin at $160^{\circ} \mathrm{C}, 170^{\circ} \mathrm{C}$ and $180^{\circ} \mathrm{C}$ cause some changes of the chemical structure of analyzed samples. It is reliable that sterilization at $160^{\circ} \mathrm{C}$ does not have any influence on the chemical stability of neomycin. The changes of intensity of the bands corresponding to $\mathrm{OH}$ group (Figures 13 and 14) can suggest dehydration with transformation of the hydroxyl groups into ethers. However, the formation of peroxides on carbon chemically bounded with two hydrogen atoms cannot be excluded. For streptomycin the increase of all difference bands (Figures 15-17) could be explained by the formation of carboxylic group from aldehyde group bounded with oxacyclopentane ring. The fact of changing the chemical structure is due to the presence of the air oxygen in sterilization conditions. Taking to account the EPR and DRIFT results, it can be concluded that streptomycin and neomycin should be sterilized at the lowest temperature of $160^{\circ} \mathrm{C}$. Thermal sterilization of gentamicin, paromomycin and tobramycin may be done at $160^{\circ} \mathrm{C}, 170^{\circ} \mathrm{C}$ or $180^{\circ} \mathrm{C}$. 
Citation: Ramos P, Pilawa B, Krztoń A, Liszka B (2012) Free Radicals in the Thermally Sterilized Aminoglycoside Antibiotics. Pharmaceut Anal Acta 3: 193. doi:10.4172/2153-2435.1000193
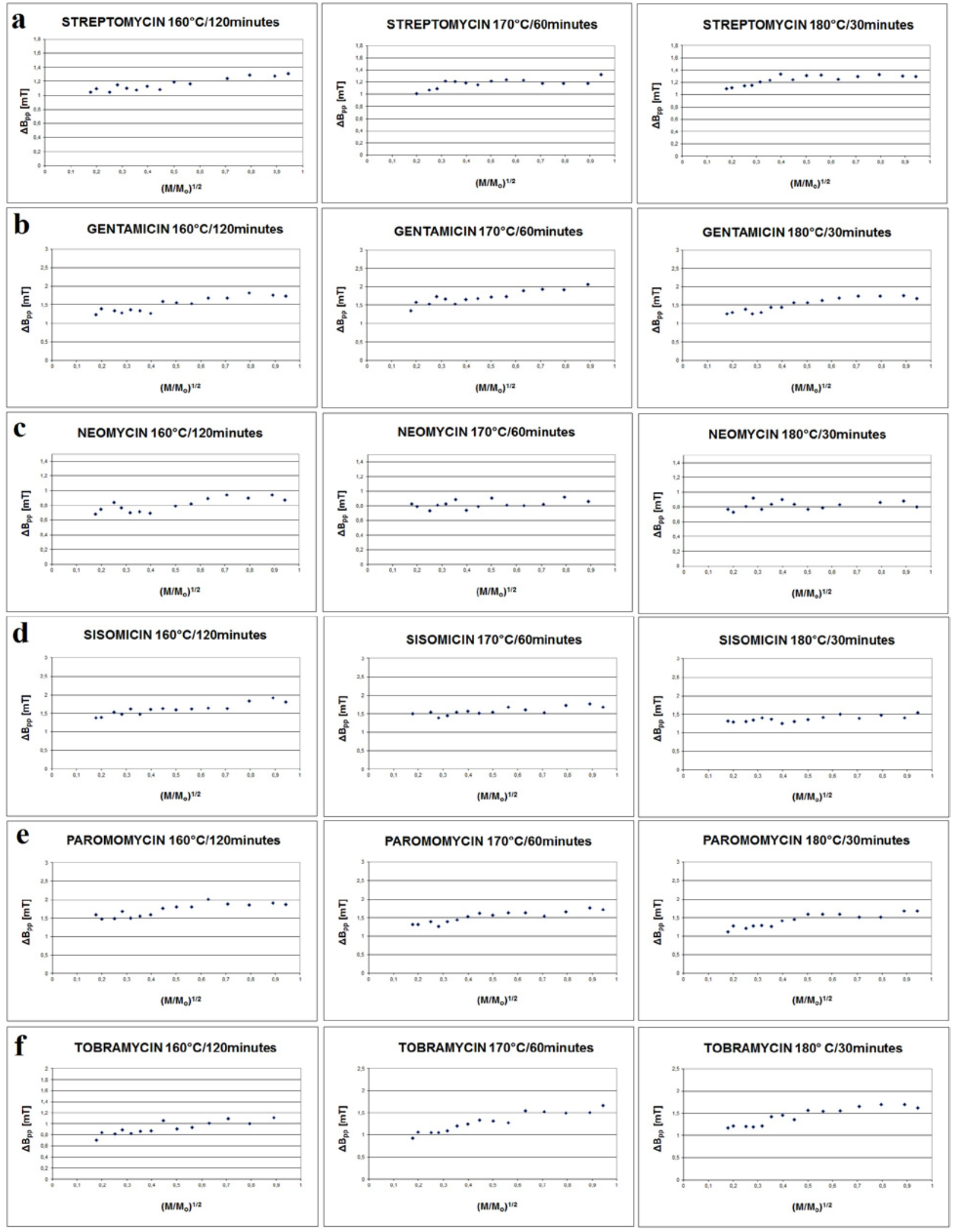

Figure 8: Effect of microwave power $\left(M / M_{0}\right)$ on linewidths $\left(\Delta B_{1}\right)$ of EPR spectra of streptomycin (a), gentamicin (b), neomycin (c), sisomicin (d), paromomycin (e), and tobramycin (f), sterilized at $160^{\circ} \mathrm{C}\left(120\right.$ minutes), $170^{\circ} \mathrm{C}\left(60\right.$ minutes), and $180^{\circ} \mathrm{C}(30$ minutes). The data for the EPR spectra measured at room temperature 20 minutes after sterilization. 


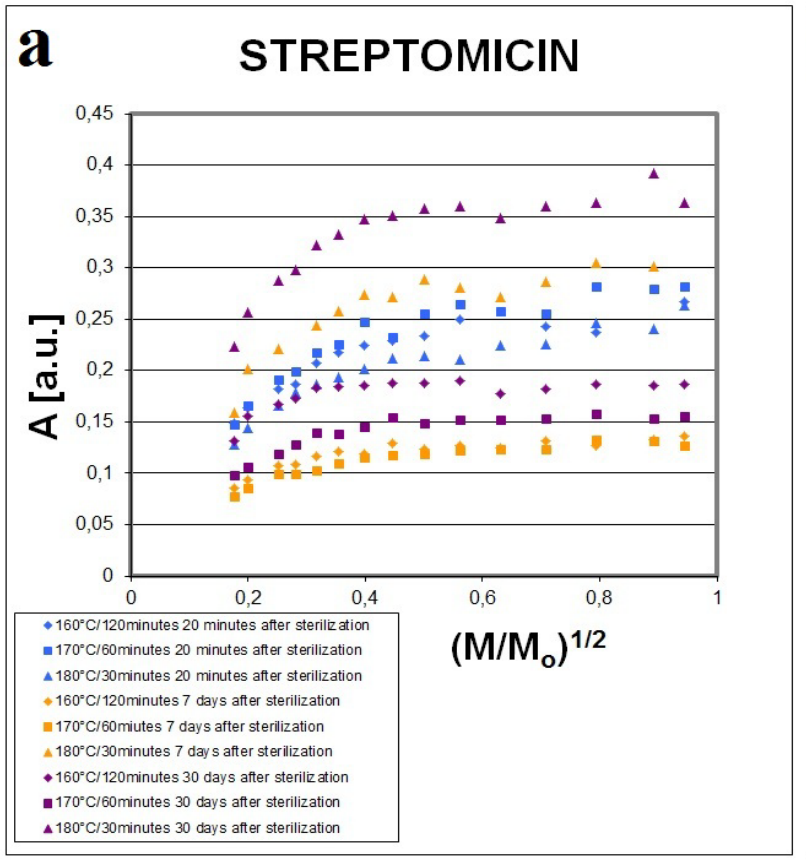

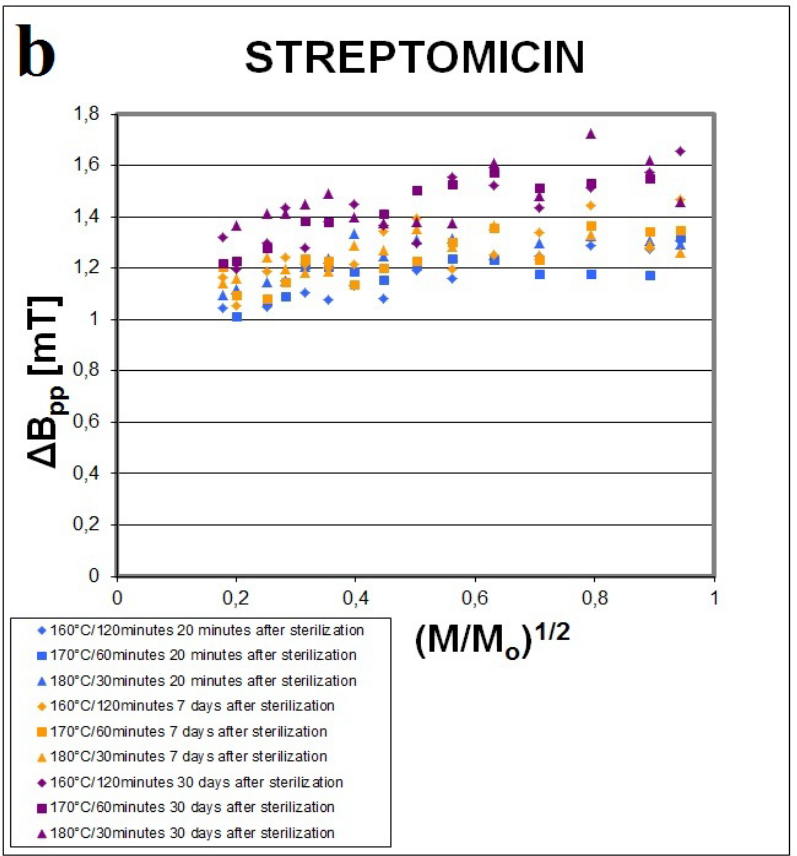

Figure 9: Effect of microwave power (M/M ) on amplitudes $(\mathrm{A})(\mathrm{a})$ and linewidths $\left(\triangle \mathrm{B}_{\mathrm{p}}\right)(\mathrm{b})$ of EPR spectra of streptomycin sterilized at $160^{\circ} \mathrm{C}\left(120\right.$ minutes), $170^{\circ} \mathrm{C}$ $\left(60\right.$ minutes), and $180^{\circ} \mathrm{C}$ (30 minutes). The data for the EPR spectra measured with microwave power of $2.2 \mathrm{~mW}$ at room temperature 20 minutes, 7 days, and 30 days after sterilization.

Free radicals concentrations formed during the sterilization process of the aminoglycoside antibiotics are not stable during the storage of these drugs after heating (Figure 9). This effect should be taking to account in the practical application of the storage drugs. It is possible that the interactions of free radicals of the sterilized antibiotics with oxygen molecules are responsible for the evolution of the concentrations of unpaired electrons in the samples (Figure 9). The interactions of free radicals with paramagnetic oxygen molecules $\mathrm{O}_{2}$ were observed for the others organic samples [14-16]. The paramagnetic organic samples interact with oxygen molecules via their unpaired electrons.

It was shown that free radicals in the analysed sterilized aminoglycoside antibiotics have the specific properties. The main feature of the paramagnetic system in the heated drugs is its complex character, which is responsible for the complex shape of the unsymmetrical EPR spectra. The shape of the EPR spectra changes with the increasing of microwave power (Figure 5), so it can be concluded that several groups of free radicals were formed during thermal sterilization of the antibiotics. It is the expected effect, because the different chemical bonds may be ruptured at the used temperatures. The chemical structures of the tested antibiotics (Figure 1) [9] points out that mainly free radicals with unpaired electrons localized on oxygen atoms are formed. The localization of unpaired electrons on carbon atoms is also possible. The oxygen and carbon free radicals are responsible for the obtained apparent g values [17-21].

DRIFT studies were carried out to address the question of how the sterilization conditions can influence on the chemical structure of aminoglycoside antibiotics. The differential spectra prove that the sterilization conditions change the chemical structure of analyzed samples. The temperature can result in dehydration results conversion of hydroxyl group to ethers in neomycin. The presence of oxygen causes the formation of peroxides in neomycin and oxidation aldehyde group to carboxylic group in streptomycin. It should be note that temperature is a decisive parameter for structural changes of neomycin during sterilization.

The continuous microwave saturation of the EPR lines (Figures 6 and 7) indicates the homogeneous broadening of these lines [12]. It is characteristic for the samples with homogenous distribution of the free radicals in their molecular units. The spin islands do not exist in the heated aminoglycoside antibiotics. This feature is the confirmation of the good performed sterilization in the antibiotics, this process was interact in the whole volume of the drugs.

Microwave power $\left(\mathrm{M} / \mathrm{M}_{\mathrm{o}}\right)$ effect on amplitudes $(\mathrm{A})$ of the EPR lines of the aminoglycoside antibiotics sterilized at $160^{\circ} \mathrm{C}, 170^{\circ} \mathrm{C}$, and $180^{\circ} \mathrm{C}$ (Figure 6) points out the fast spin-lattice relaxation processes in the samples. The microwave saturation of the EPR lines are not observed, the amplitudes increase with the increasing of microwave power the used range of its values (up to $70 \mathrm{~mW}$ ) (Figure 6). For the fast relaxing systems unpaired electrons excited by microwaves fast come back to the ground energy levels [12]. Similar fast spin-lattice relaxation processes were observed for thermally sterilized prednizolone [4], diclofenac [5], tramadole [6] and isosorbidedinitrate [7].

Spectroscopic analysis performed in this work show that both EPR and DRIFT methods may be proposed as the additional ones to obtain the best conditions of the thermal sterilization of drugs. The aim of the EPR and DRIFT measurements is to choose the optimal temperature and time of sterilization of the individual drugs from the proposed by the pharmaceutical norms. EPR and DRIFT spectroscopy may be applied to compare chemical structure and free radicals in the original and thermally treated drugs. Sterilization process should not modify the chemical structure of the drugs and should not form free radicals in them. 


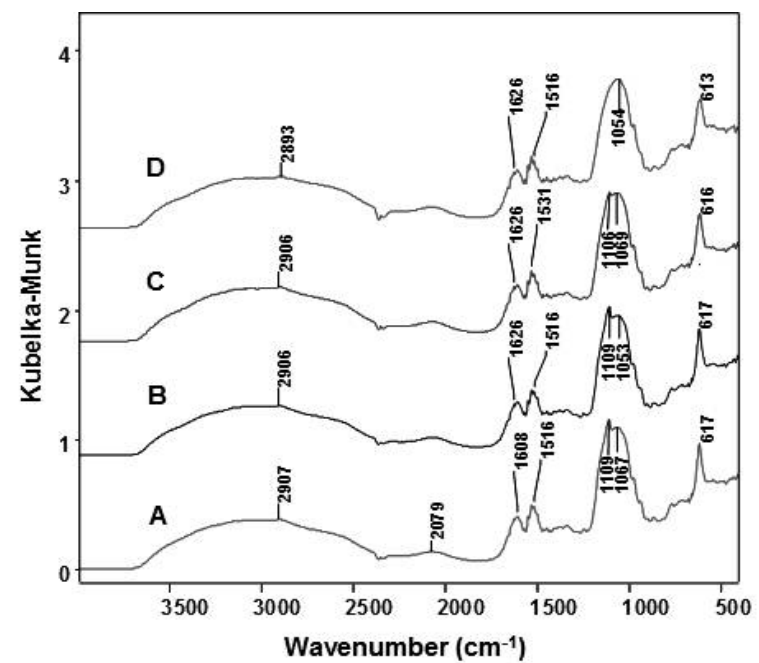

Figure 10: DRIFT spectra of non-sterilized neomycin - $\mathrm{A}$, and neomycin sterilized at $160^{\circ} \mathrm{C}(120$ minutes $)-B, 170^{\circ} \mathrm{C}(60$ minutes $)-C$ and $180^{\circ} \mathrm{C}(30$ minutes) - D.

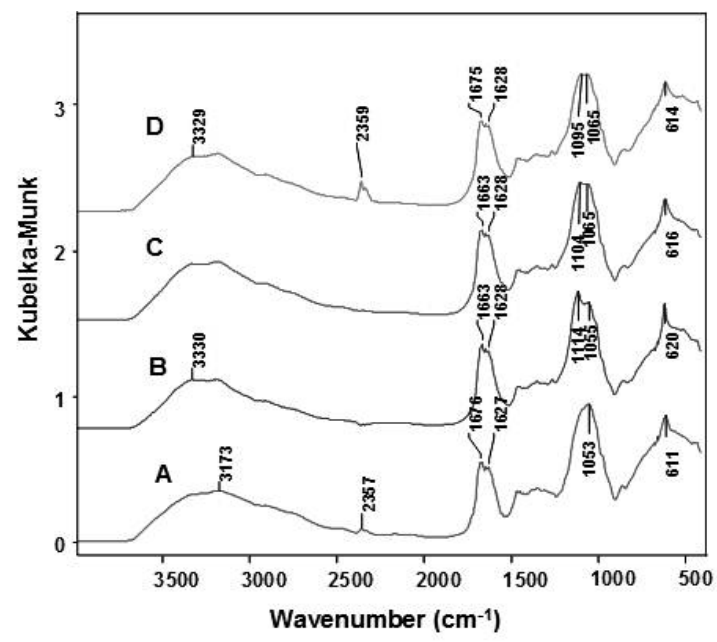

Figure 11: DRIFT spectra of non-sterilized streptomycin - $A$, and streptomycin sterilized at $160^{\circ} \mathrm{C}\left(120\right.$ minutes) - B, $170^{\circ} \mathrm{C}$ (60 minutes) - C and $180^{\circ} \mathrm{C}(30$ minutes $)-\mathrm{D}$.

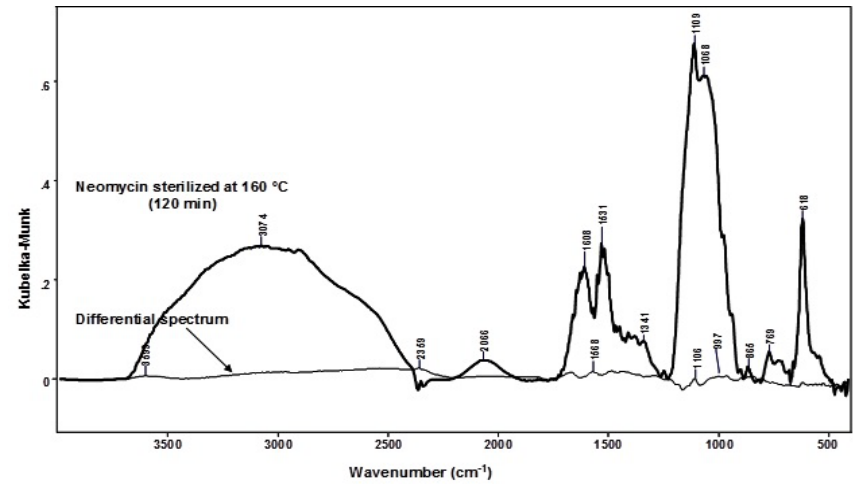

Figure 12: DRIFT spectra and differential spectra of neomycin sterilized at $160^{\circ} \mathrm{C}$ (120 minutes).

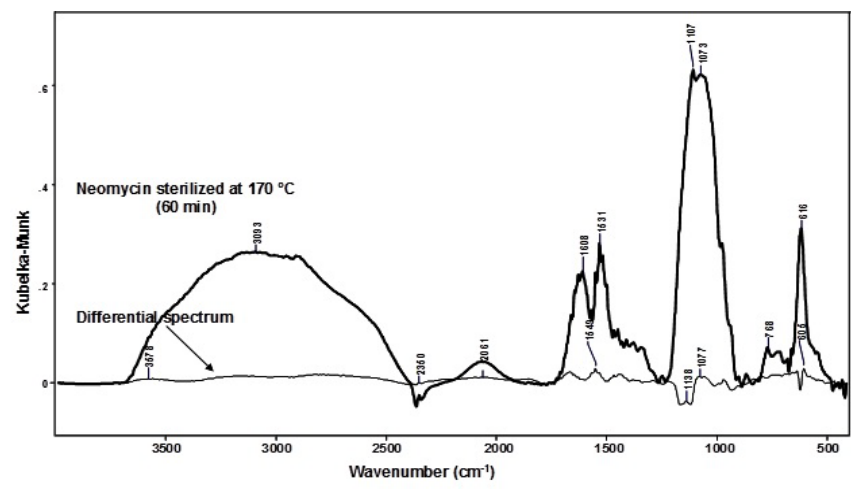

Figure 13: DRIFT spectra and differential spectra of neomycin sterilized at $170^{\circ} \mathrm{C}$ (60 minutes).

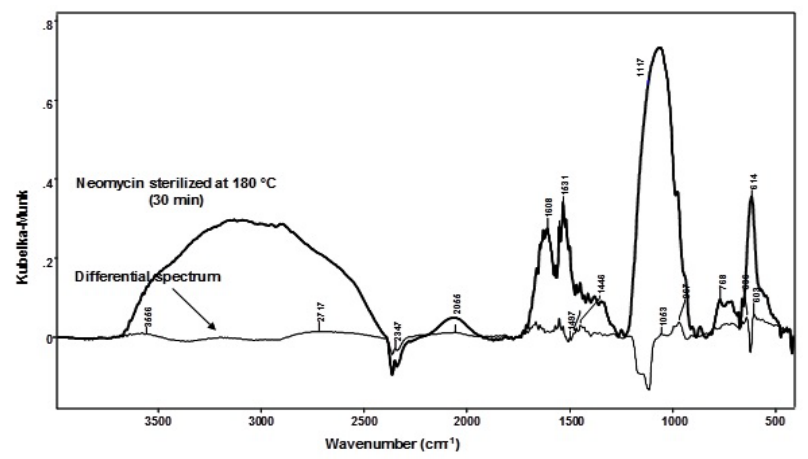

Figure 14: DRIFT spectra and differential spectra of neomycin sterilized at $180^{\circ} \mathrm{C}$ (30 minutes).

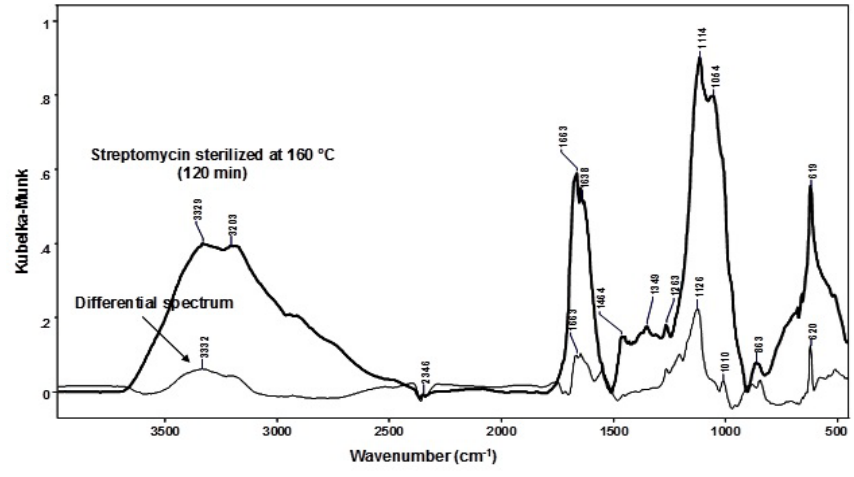

Figure 15: DRIFT spectra and differential spectra of streptomycin sterilized at $160^{\circ} \mathrm{C}$ (120 minutes)

\section{Conclusion}

The performed EPR and DRIFT studies of the thermally sterilized aminoglycoside antibiotics indicate that:

1. Free radicals are formed in streptomycin, gentamicin, neomycin, sisomicin, paromomycin, and tobramycin during thermal sterilization at temperatures $160^{\circ} \mathrm{C}, 170^{\circ} \mathrm{C}$ and $180^{\circ} \mathrm{C}$ as EPR measured spectra shown. 


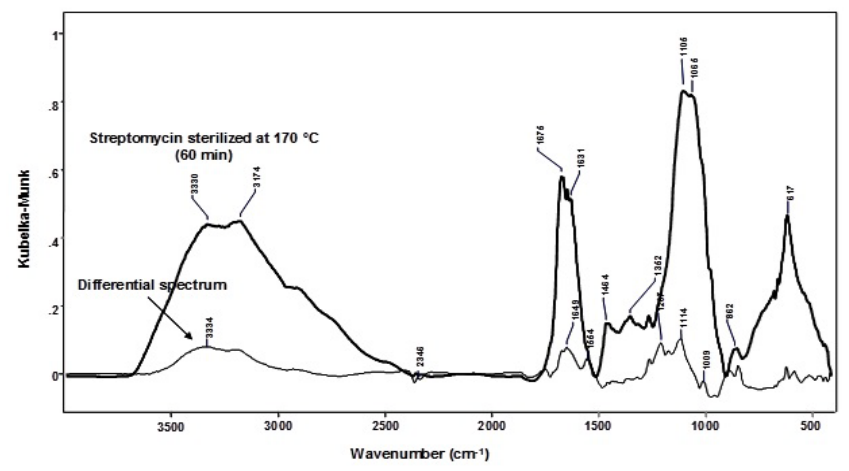

Figure 16: DRIFT spectra and differential spectra of streptomycin sterilized at $170^{\circ} \mathrm{C}(60$ minutes).

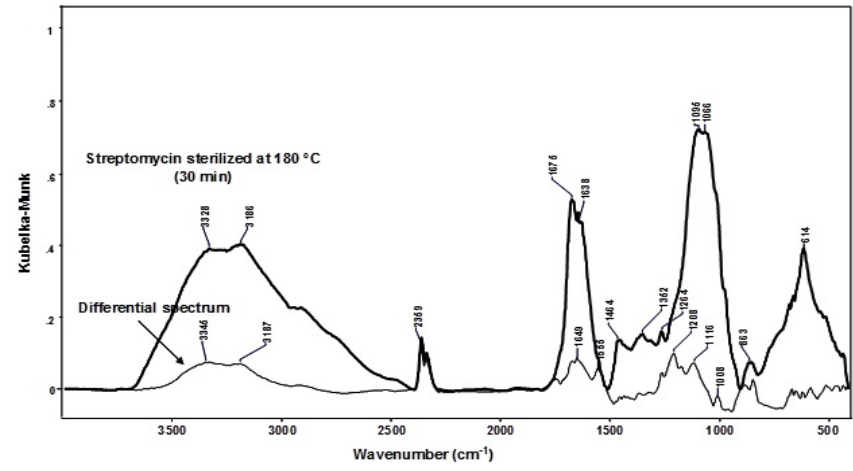

Figure 17: DRIFT spectra and differential spectra of streptomycin sterilized at $180^{\circ} \mathrm{C}$ (30 minutes).

2. Free radicals in the sterilized aminoglycoside antibiotics reveal the following properties:

- complex character of free radicals system with the complex shape of EPR spectra,

- mainly oxygen free radicals exist in the tested heated antibiotics,

- homogeneous broadening of EPR lines, proved by the continuous microwave saturation of the resonance signals, and

- fast spin-lattice relaxation processes without microwave saturation of the EPR lines in the used range of microwave powers.

3. Free radicals concentrations in the aminoglycoside antibiotics depend on the temperature and time of sterilization. The highest free radicals concentrations characterize thermally sterilized sisomicin.

4. Gentamicin, paromomycin, and tobramycin may be sterilized at temperatures $160^{\circ} \mathrm{C}, 170^{\circ} \mathrm{C}$ and $180^{\circ} \mathrm{C}$. Streptomycin and neomycin should be sterilized at $160^{\circ} \mathrm{C}$. For sisomicin thermal sterilization at temperature $180^{\circ} \mathrm{C}$ for is recommended.

5. Free radicals concentrations changes during storage of the examined antibiotics, and probably interactions with oxygen molecules may be responsible for this effect.

6. The DRIFT results assumed that effect of the temperature and the presence of oxygen in process sterilization causes only small changes in the chemical structure of aminoglycoside antibiotics by alteration of the functional groups. It is suggested that the sterilization conditions contribute to the formation some new ether groups (by dehydration of hydroxyl groups) in neomycin and carboxylic group (by oxidation of aldehyde group) in streptomycin. It is not excluded also formation of peroxides in neomycin. However, the chemical structure of neomycin is stable in sterilization at $160^{\circ} \mathrm{C}$.

7. The results support the assumption that EPR and DRIFT methods may be used for optimization of thermal sterilization process of drugs and conditions of their storage.

\section{Acknowledgement}

This study was supported by Medical University of Silesia in Katowice Grant No. KNW-1-002/P/2/0".

\section{References}

1. Barteczko I (2002) Farmacja stosowana, PZWL, Warszawa.

2. Farmakopea polska (2009) wydanie VIII. PTFarm, Warszawa

3. PN-EN 556, 2005. Sterylizacja wyrobów medycznych. Wymagania dotyczace wyrobów medycznych określanych, jako STERYLNE. Część 2: Wymagania dotyczące wyrobów medycznych wytwarzanych w warunkach aseptycznych, Warszawa, Polski Komitet Normalizacyjny, 2002 (in Polish).

4. Kościelniak M, Wilczyński S, Pilawa B (2008) Free radicals in thermally sterilized prednisolone. Eng Biomater XI (81-84) 61-62.

5. Pilawa B, Ramos P, Wilczyński S, Czyż K (2008) Free radicals system analysis for thermally sterilized diclofenac. Eng Biomater XI (81-84) 57-58.

6. Pilawa B, Wilczyński S, Ramos P, TomasikA (2008) Evaluation of concentration stability and types of free radicals generated in tramadole exposed to high temperature. Eng Biomater XI(81-84) 63-64.

7. Ramos P, Pilawa B (2009) Influence of temperature and time for sterilization to generate free radicals in diazotanieizosorbitolu. Farm Science Review of $R$ 7: 28-33.

8. Bartosz G (2004) The other face of oxygen. PWN, Warszawa.

9. Zejc A, Gorczyca M (2004) Chemical drugs. PZWL, Warszawa.

10. Janiec W, Krupińska J (1999) Pharmacodynamics. PZWL, Warszawa

11. Kostowski W, Herman SZ (2007) Farmakologia. PZWL, Warszawa.

12. Wertz JE, Bolton JR (1986) Electron Spin Resonance Theory and Practica Applications, Wiley-Interscience, New York, London.

13. Eaton GR, Eaton SS, Salikhov KM (1998) Foundations of modern EPR, World Scientific, Singapore, New Jersey, London, Hong Kong.

14. Griffiths PR, Haseth JA (1986) Fourier Transform Infrared Spectrometry. Wiley New York.

15. Bellami LJ (1975) The Infrared Spectra of Complex Molecules. Chapman and Hall, London.

16. Dzherayan TG, Bykov IV, Kostitsyna MV, Shipulo EV, Petrukhin OM, et al. (2010) Study of a gentamicin-selective membrane polymer matrix by Infrared spectroscopy. J Anal Chem 65: 726-731.

17. Kim D, Kim S, Jo S, Woo J, Noh I (2011) Effect of cross-linking spacers on biocompatibility of chitosan-spacer-poly(ethylene oxide) hydrogel. Macro Res 19: $573-581$.

18. Zhao X, Li Z, Liu W, Lam W, Sun P, et al. (2011) Octaarginine-modified chitosan as a nonviral gene delivery vector: properties and in vitro transfection efficiency. J Nanopart Res 13: 693-702.

19. Pilawa B, Latocha M, Buszman E, Wilczok T (2003) Effect of oxygen on spinspin and spin-lattice relaxation in DOPA-melanin, Complexes with chloroquine and metal ions. Appl Mag Res 25: 105-111.

20. Pilawa B, Pietrzak R, Wachowska H, Babeł K (2005) EPR studies of carbonized cellulose - oxygen interactions. Acta Phys Polon A 108: 151-154.

21. Pilawa B, Wieckowski AB, Pietrzak R, Wachowska H (2007) Microwave saturation of EPR spectra of oxidised coal. Cent Eur J Chem 5: 330-340. 